\title{
Aesthetic Unrest: "Howl” and the Literary List
}

Alyson Brickey

At the still point of the turning world. Neither flesh nor fleshless;

Neither from nor towards; at the still point, there the dance is, But neither arrest nor movement. And do not call it fixity.

-T.S. Eliot, "Burnt Norton"

Lists are everywhere these days: not just in the familiar capitalist forms of "best seller" lists or "best albums of the year" lists, but most ubiquitously on the internet, in the form of the increasingly popular "listicle." As Wikipedia defines it, "[t]he word is a portmanteau derived from list and article. It has also been suggested that the word evokes 'popsicle,' emphasizing the fun but 'not too nutritious' nature of the listicle."' The listicle is an easily digestible, tasty treat. It allows us to take in a large concept in a small delicious form - an innocuous distillation of a more complex process of knowledge production. The less serious partner in the pair is, of course, the list, not the article. Lists are direct and to-the-point. They are

\footnotetext{
A. Brickey $(\bowtie)$

Department of English, University of Winnipeg, Winnipeg, MB, Canada e-mail: a.brickey@uwinnipeg.ca

(C) The Author(s) 2022

R. A. Barton et al. (eds.), Forms of List-Making: Epistemic, Literary, and Visual Enumeration, https://doi.org/10.1007/978-3-030-76970-3_8
} 
brief, ordered, and clear, and they do not pretend to do the lofty intellectual work of a longer article or more involved piece of writing.

Recent scholarship on the form and function of the list, however, would suggest that lists are not, after all, to be trusted. In their introduction to the February 2016 special issue of Society and Space, "The Politics of the List," Marieke de Goede, Anna Leander, and Gavin Sullivan argue that lists are in fact quite nefarious. The cultural proliferation of lists, they suggest, which

is taking place across such diverse domains $[\ldots]$ as finance, the environment, security, humanitarianism and health, $[\ldots]$ should be treated as more than a curiosity. Instead, we argue that it is important to take seriously the form and technique of the list itself and engage the knowledge practices, governance effects and ways of ordering the world that the list format enables. $(2016,3-4)$

Citing examples such as watch lists, kill lists, blacklists, and no-fly lists, contributors to this special issue each elaborate what they believe to be the list's culturally oppressive characteristics: its ability to "procedure categories by making a 'cut' in the continuous flow of the world," its power to include through exclusion, and its suitability to processes which discursively restructure the world in order to benefit those in power (De Goede et al. 2016,6).

This is something Michel Foucault intuits in much of his work, most notably in The Order of Things, where he outlines the epistemic processes that occasioned science's penchant, for example, for constituting the very knowledge systems that would make its "discoveries" possible. But the list, it is worth remembering, manifests in many different cultural forms, not just in science and law and finance. We also see it in aesthetic practices and artistic representations, where its ability to "cut" in the way these writers identify is complicated, and even encumbered. Umberto Eco's 2009 monograph The Infinity of Lists as well as the 2016 special issue of Style devoted to the range of literary lists throughout genres and history are a testament to this fact.

Eco distinguishes between what he calls "pragmatic" and "poetic" lists. Pragmatic lists are the kind of lists which are mundane and familiar, like telephone directories or restaurant menus. Eco argues that these kinds of lists "confer unity," and are therefore also finite $(2009,113)$. Poetic lists, on the other hand, are insatiable in their scope. These lists gesture outward into an abyss of referentiality and can expand infinitely. It is this 
second kind of list - the poetic list—with which this chapter concerns itself. While the writers in Society and Space argue that Eco's categories obscure the powerful ideological work that the list as a cultural technology does, suggesting that he makes a problematic distinction between high and low art, I argue that the literary list can in fact offer us a way of combating those same power structures with which these contributors are so concerned. Lists initiate a kind of restlessness within the literary text: what I term, in what follows, an "aesthetic unrest."

To elucidate this idea, I take up Allen Ginsberg's 1956 poem "Howl", a deviously restless text. This poem is constantly experimenting with movement and motion, its subjects caught up in continuous verbs, performing illicit acts and living in ways that defy state-sanctioned norms of behavior. To contextualize this kinesis, I turn to literary theory's interest in the aesthetic history of ekphrasis, or the linguistic representation of a visual representation. The literary list, I suggest, involves recourse to what Leo Spitzer calls the "ekphrastic impulse," which is a kind of representational reach for mimesis which always falls short and is therefore always also on the move $(1962,266)$.

In his discussion of literary ekphrasis, Sigurd Burckhardt positions literary works as materially unmoored, constantly searching for some reconnection to the physical world through linguistic attachment. The process of ekphrasis thus becomes a larger organizing principle, where all literary art in some sense desires to be a plastic art, and where poems can be said to have an "impulse" that tends toward the materially solid medium of sculpture. What is most relevant for my current discussion is the formulation of this impulse as an interplay between stillness and movement. To describe this phenomenon, Murray Krieger uses the term "still" not just as an adjective, but also as an

adverb, and verb; as still movement, still moving, and more forcefully, the stilling of movement: so "still" movement as quiet, unmoving movement; "still" moving as a forever-now movement, always in process, unending; and the union of these meanings at once twin and opposed in the "stilling" of movement, an action that is at once the quieting of movement and the perpetuation of it, the making of it; $[\ldots]$ a movement that is still and that is still with us, that is—in [Eliot's] words, "forever still." (Krieger 2019, 268)

This is Eliot's “still point of the turning world" from his 1936 poem "Burnt Norton": neither stasis nor momentum; not aesthetic arrest, but a 
kind of aesthetic unrest (Eliot 2008, 64). This paradoxical, ekphrastic quality of literature is precisely the movement that the aesthetic category of the literary list can lay bare. Lists like Ginsberg's poetically enact strange scenes that are "still moving" in their stillness. They can open a space amongst a flurry of activity: a productive space where the book exposes us, in these moments of unrest, to some kind of otherness-something strange.

This type of internal vibration-this textual restlessness that we see in Ginsberg's ecstatic chants of "holy! holy! holy!"-is indicative of an ekphrastic kinesis: a literary marker of the difficulty inherent within the process of representation itself $(2008 \mathrm{a}, 1)$. In many ways, lists stall us, leaving us stuck between things; moored in the interstitial spaces between two or more solid, definable concepts. This is not stasis, however; and we do not experience a Joycean aesthetic arrest. It is a dynamic energy that lies at the very center of the work, and it is born out in catalogue form. In our encounters with texts like "Howl," we are thus witness to an aesthetic unrest: an inner oscillation that might trouble us or strike us as strange, or off-kilter. The a-narrative character of the list lends itself to this version of estrangement, but so do its ties to textual over-population, paratactic prose, and excessive descriptive passages that we might even find boring, or frustratingly unfocused.

The encounter with the list is also importantly a process of alienation and, as I show, is structurally aligned with the dynamics inherent in contemporary theoretical conceptions of ethical responsibility. Since at least Emmanuel Levinas's work in the 1950s, the philosophical conception of an ethical encounter has involved the idea of an encounter with otherness-something or someone who is strange and unfamiliar. Restless lists like the ones we find in "Howl" are, I suggest, one way that literature can expose us to otherness: that which is strange and outside of our familiar field of vision. The literary listing we find in "Howl" is strange-queer, even-not just for its evocation of sexual non-conformance, but also, importantly, for its ability to tolerate a kind of constant unease: an ontological restlessness born out in its catalogue aesthetic.

When Joyce's protagonist Stephen Dedalus lays out his aesthetic philosophy to his friend Lynch at boarding school in A Portrait of the Artist as a Young Man, he identifies an "esthetic emotion" that he says is "statica face looking two ways $[\ldots]$ the mind is arrested and raised above desire and loathing" (Joyce 2003, 222). This passage marks the first time in literature we encounter the now-familiar idea of "aesthetic arrest," a concept 
that seems to name that which we have understood for so long in our philosophical discussions about art: a description of stillness in the face of beauty-an automatic response to being in the presence of artwork that moves.

The temporal and grammatical aspects of "Howl" accrue an intensity and velocity as the text progresses. Ginsberg, as many scholars have noted, was very interested in rhythm and music while writing this piece, and was particularly fond of listening to jazz great Charlie Parker while he composed his lines (see Géfin 2002, 275). Parker is perhaps most famous for his piece "Now's The Time," which aligns both thematically and formally with Ginsberg's repeated use of the continuous present tense in "Howl," as well as its simultaneity. Though he begins in the past tense, with the elegiac "I saw the best minds of my generation destroyed by madness," Ginsberg immediately shifts to the continuous present with "starving / hysterical, naked, / dragging themselves through negro streets at dawn looking for an angry / fix / [...] burning for the ancient heavenly connection" $(2008 \mathrm{~b}, 1-2)$. And while the tense shifts effortlessly throughout the poem-between different variations of the past, present, and future-it is always in the service of presenting us with extremely dynamic and perpetually moving scenes, not unlike the dynamism for which jazz music is known.

Each of these scenes is anchored by a strong verb that is very often connected to a description of an emotional force or corporeal movement. Ginsberg's rebellious young men over-populate the page with their insistent activity, which more often than not stages a socially taboo scenario. These are actors who shun heteronormativity and reject capitalist conformity. They press and impress upon us with an often violent and desperate demand for recognition and space. This is not the plural America that a loafing Walt Whitman described as his toes curled lazily in the grass; this is an America filled with young urban men on fire. These are men who chain themselves to subways, fuck each other in the ass, "walk all night with their shoes full of blood," burn cigarette holes in their arms, and "cut their wrists three times successively unsuccessfully" in a kind of living that might actually lie just adjacent to a kind of dying (Ginsberg 2008b, 44, 55).

In essence, Ginsberg presents us with a great list of unapologetically frenetic moments. When placed successively one after another, these moments accumulate to form a complex and perpetually moving scene. Ginsberg's aesthetic in fact operates in much the same manner here. Each line sets another action in motion, and these individual movements 
accumulate and gain momentum as the piece progresses. This process has something to do with the affective momentum of the poem as well, and by the end of the piece, when we read the supplementary "Footnote to Howl" where Ginsberg ecstatically declares that everything and everyone is "holy," we feel the weight of all that has come before it and are left with little choice but to join in, echoing his chant.

The rhythms he was encountering in Black Jazz culture, Ginsberg attempted to make each line the length of one long breath, a technique that infuses the poem with a steady pace that at once feels natural, but also always new (Géfin 2002, 275). In the first section, many lines start with the anaphoric "who," followed by some physical action performed by that subject, and then ending with an elaboration on that action. Here is a typical example: "who scribbled all night rocking and rolling over lofty incantations which in the yellow morning were stanzas of gibberish" (Ginsberg 2008 b, 5l). If we temporarily remove each elaboration, it becomes even more clear that the poem is asking us to recognize not just these subjects who society wants to marginalize and denigrate, but also to accept, without condition, their often brazen and illicit actions. Ginsberg wants to lift these scenes out of the shamefulness of dark corners and display them, glorified, upon a stark white page. Like Whitman's great catalogues in "Song of Myself" that expand to accommodate both the prostitute and the President, Ginsberg wants to invite those

who blew $/[\ldots]$ who balled $/[\ldots]$ who hiccupped $/[\ldots]$ who lost $/[\ldots]$ who copulated $/[\ldots]$ who sweetened $/[\ldots]$ who faded $/[\ldots]$ who walked $/$ $[\ldots]$ who ate $/[\ldots]$ who wept $/[\ldots]$ who scribbled $/[\ldots]$ who cooked $/[\ldots]$ who plunged $/[\ldots]$ who threw $/[\ldots]$ who cut $/[\ldots]$ who sang $/[\ldots]$ who drove $/[\ldots]$ who journeyed $/[\ldots]$ who crashed $/[\ldots]$ who demanded (2008b, 36-64)

and so on. These men and many more initiate moments of activity that defy prescriptive gender norms, balk at heteronormative coupling, spit at mandatory capitalist labor, howl back against the violence of war, and think anew what it might mean to live life otherwise.

"Howl" was written against the backdrop of a dominant American culture that was increasingly conservative, valuing conformity and control amidst the traumatic reverberations of World War II. Having just come out of a university experience studying English literature at Columbia, Ginsberg was frustrated by what he saw as the stale formalism of American poetry and disillusioned by higher education's ideological and financial 
involvement with the perverse creation of the atomic bomb. Written on the cusp of the repressive social policies of the Cold War, "Howl" represents a political, but not a utopian gesture. It reaches not toward some future time when differences would be tolerated and all would be harmonious, but rather enacts a powerful legitimization of a present moment that was being over-written by a rising white, patriarchal, upper middleclass, heterosexist culture. This is a type of resistance through the rebellion of contemporaneity: now was going to be the time when disaffected and disenfranchised populations were going to be taken seriously, just as Martin Luther King Jr. would articulate a short eight years later on the steps of the Washington Monument. ${ }^{2}$

While Ginsberg is not explicitly aligning himself with any particular political movement per se, there is nonetheless a politics here that has to do with a validation of subjects or ways of being that have been culturally suppressed or ideologically vilified. While the Society and Space editors are right to connect the list to politics, Ginsberg here demonstrates that the form can also be instrumentalized to fight against the very oppressive mechanisms they identify in their critique.

This last point becomes especially clear in Part III of the poem, which is addressed directly to Carl Solomon. Solomon was at the time incarcerated in a state-run psychiatric institution, and Ginsberg had in fact met him at a similar hospital in 1949 (see Hunsberger 2002, 160). This third section of the poem starts by continuing the radical dynamism I have been tracing, where lists of verbs and actors in constant and varied motion pile up, one on top of the other, multiplying and rapidly proliferating like errant cells under a microscope. These lines are filled with subjects who are nearly moving too fast for us to see; people who

talked continuously seventy hours from park to pad to bar to Bellevue to museum to the Brooklyn Bridge,

a lost battalion of platonic conversationalists jumping down the stoops off

fire escapes off windowsills off Empire State out of the moon, yacketayakking screaming vomiting whispering facts and memories and anecdotes and

eyeball kicks and shocks of hospitals and jails and wars, $[\ldots]$

who lit cigarettes in boxcars boxcars boxcars racketing through snow toward lonesome farms in grandfather night, who studied Plotinus Poe St. John of the Cross telepathy and bop kaballah because the cosmos instinctively vibrated at their feet in Kansas. (Ginsberg 2008b, 16-24) 
Ginsberg's dual focus on simultaneity and movement comes strongly to the fore in this excerpt, as catalogues of verbs spill forth in clusters like "screaming vomiting whispering," and we are overwhelmed by having to imagine how one body could be doing all of this at once. It is as if he places multiple spinning tops on a vast floor, and one by one sets each in motion until the entire room is abuzz with kinetic activity. This sense of a cyclical rather than a propulsive movement is linguistically enacted through repetitive lines such as "who lit cigarettes in boxcars boxcars boxcars racketing through snow," which at once conjures the sound and rhythm of a forward-moving train, but also stalls the semantic progression of the sentence through repetition, and asks us to stay, moving, in the present moment (Ginsberg 2008b, 23).

While section one is filled with rebellious and subversive activity, and section two (the "Moloch" section) realizes an Inferno-like representational diagnosis of contemporary America's most insidious socio-cultural problems, section three is, by contrast, very calm and gentle in its tone. Here, Ginsberg stages a scene between just two characters, and in doing so he also stages a scene between freedom and confinement-power and powerlessness.

The section starts empathetically, where the "with" signals a kind of emotional alignment or understanding - an attempt to let the other know that he is not, in the end, alone. "I'm with you in Rockland," the speaker says over and over again,

where you must feel very strange

I'm with you in Rockland

where you imitate the shade of my mother

I'm with you in Rockland

where you've murdered your twelve secretaries

I'm with you in Rockland

where you laugh at this invisible humor

I'm with you in Rockland

where we are great writers on the same dreadful typewriter

I'm with you in Rockland

where your condition has become serious and is reported on the radio.

(Ginsberg 2008b, 96-106)

While the initial deictic location of the sentence is tied to the speaker-the "I" who is claiming to be "with" Solomon-the second line always shifts to the second person "you," emphasizing the importance of trying to 
understand the strangeness of being institutionalized: the perspective from which Solomon must be experiencing the world while detained in this place. Rightly or wrongly, this "I" attempts to reside in Solomon's head, taking seriously his delusions and participating in what others might think are mad, impossible scenes. Ginsberg imagines what it would be like if Solomon were not tucked quietly away and isolated, but rather treated as if his crisis were global in scale, as serious as an earthquake or another natural disaster that might be "reported on the radio."

The most powerful line of this section enacts another kind of ontological validation, but here this is accomplished through rhetorical recourse to a kind of ethical imperative. Solomon "bang[s] on the catatonic piano," spelling out a song that no one but the speaker seems able to translate, and stuck in a rhythmic yet torturous holding pattern (Ginsberg 2008b, 116). Catatonia is a kind of "inert state" characterized by the inability to move in recognizably normative physical and behavioral patterns. ${ }^{3}$ In keeping with his theme, however, Ginsberg aestheticizes this inertness and turns it into inertia; he transforms Solomon's mental state into music, so that catatonia might now sound like a song where one note is repeated again and again, not unlike the poem's anaphoras. What results is an urgent moral statement: a run-on sentence that tells a tragic narrative and signals a need for change and recognition. "The soul," Ginsberg concludes, "is innocent and immortal it should never die ungodly in an armed madhouse" (Ginsberg 2008b, 116). This is a restlessness and unease that results in sympathetic care; the familial tone with which this stanza begins-the sibling-like adjacency that Ginsberg creates-now shifts to a guarding, parental one. This paves the way for the next few lines that seem to momentarily break from the willingness to inhabit Solomon's delusions to a more direct indictment of the realities of state-run psychiatric care. Again the speaker is "with" Solomon in Rockland, but now we are made to face directly the effects of institutionalized violence, when "fifty more shocks will never return your soul to its body again" (Ginsberg 2008b, 117).

Lest he create a hopeless scene, however, Ginsberg ends this section with a dream for a different reality, one where those imprisoned in Rockland break free from its oppressive walls and emerge triumphant to the soundtrack of a different kind of national anthem. The walls turn "imaginary" and collapse, and airplanes "roar over the roof" and drop "angelic bombs" (Ginsberg 2008b, 127). And as if the familiar orchestral swell of the Star-Spangled Banner has slowly crept into the frame, we read "O skinny legions run outside / O starry-spangled shock of mercy the 
eternal war is here / O victory forget your underwear we're free" (Ginsberg 2008 b, 129). Ginsberg does not end with an unproblematic image of emancipation. Instead, he stages a quiet, private meeting, where he and Solomon can greet one another on equal footing, if only in an imagined space. "In my dreams," the speaker says, "you walk dripping from a seajourney on the highway across America in tears to the door of my cottage in the Western night" (Ginsberg 2008b, 130).

The supplementary "Footnote to Howl" functions as a vital addition to the rest of the text. Ginsberg does not just make everything democratically equal, however, and he does not reach for the mechanical political metaphors he uses in other poems, like "Wichita Vortex Sutra"-words like ("legislate [...] execute [...] publish," or "approve") $)^{4}(2007,402)$. Instead, he declares that everything is sacred; holy:

Holy! Holy! Holy! Holy! Holy! Holy! Holy! Holy! Holy! Holy! Holy! Holy! Holy! Holy! Holy! Holy!

The world is holy! The soul is holy! The skin is holy! The nose is holy! The tongue and cock and hand and asshole holy!

Everything is holy! everybody's holy! Everything is holy! everybody's holy! everywhere is holy! everyday is in eternity! Everyman's an angel!

The bum's as holy as the seraphim! the madman is holy as you are my soul are holy!

The typewriter is holy the poem is holy the voice is holy the hearers are holy the ecstasy is holy! (Ginsberg 2008a, 3-5)

This is a forceful and rebellious prayer: a sacrilegious, liturgical celebration. Here Ginsberg's parataxis works to linguistically and rhythmically equalize the poem's inhabitants - the nose and bum are praised alongside seraphims and angels - and capitalized letters fall away in favor of nonhierarchical lower-case ones. Through a whirling sea of individual actions and queer voices and incomprehensibly mad gestures, Ginsberg has made everything and everyone holy, and he has opened up a space where Carl Solomon can emerge from the sea and walk tearfully up to his cabin door in the middle of the quiet night. Ginsberg imagines a space that is hospitable even for those who have been cast away or cast out. His America is one where "when you are not safe I am not safe," and "Howl" thus remains a truly radical poetic offering.

Timothy Morton connects the notion of hospitality and what he calls "queer ecology." "To us," he argues, 
life-forms are strangers whose strangeness is irreducible: arrivants, whose arrival cannot be predicted or accounted for ("Hostipitality"). Instead of reducing everything to sameness, ecological interdependence multiplies differences everywhere $[\ldots]$ Strange strangers are uncanny, familiar and strange simultaneously. [...] They cannot be thought as part of a series (such as species or genus) without violence. [...] Queer ecology may espouse something very different from individualism. (Morton 2012, 277)

Here is a model of sociality that is paradoxically based on strangeness, not familiarity or understanding. Lists, in many ways, are indeed very queer. They too "multiply differences" and render the world mysterious and miraculous. They can make even the most familiar collection of things seem weird in its heterogeneity, and they can make the most bizarre things appear familiar through a cultural attachment to modes of description and definition. Ginsberg's list aesthetic, in other words, is one way representations can register that version of the uncanny that Morton identifies. Lists invite us to reconsider those familiar processes by which we are accustomed to recognizing and responding to that which is strange, other, queer, and unfamiliar.

And while the list does not necessarily entail an ethics in every circumstance, lists like Ginsberg's suggest that the aesthetic deployment of the catalogue form is not in itself harmful. It can, in fact, be quite revolutionary. This challenges the arguments made in Society and Space, and yet the contributors are correct in exposing the list's complicity in some extremely harmful social practices. While it is true that the catalogue form may serve oppressive aims by enabling the production of "contingent referentialities that come to appear as obvious," "absorb[ing] uncertainty," and "undermining the possibilities for political challenge," it is also true that the list can open up the possibility of radically shifting the ground upon which those kinds of aims are able to proliferate-where categories like "citizen" and "non-citizen," become very difficult to delineate and maintain (De Goede et al. 2016, 3, 6, 7).

It is in this sense that Ginsberg's lists strike us. They repeatedly disrupt any kind of linearity and can disturb conceptual associations. They overwhelm us and flood us with too much information and make navigating a textual world a disorienting and unfamiliar process. The contemporary philosophical formulation of otherness as strange carries with it an implicit demand that we must never try to domesticate or familiarize it. Giorgio Agamben writes, for example, that "if we try to grasp a concept as such, it 
is fatally transformed into an object, and the price we pay is no longer being able to distinguish it from the conceived thing" $(2003,80-81)$. The question becomes how best, then, to avoid collapsing the distance between the thing and the mimetic representation of the thing-between alterity and our ability to name it. Ginsburg's lists may offer us one way to think about that strange process of an encounter with alterity that is also, at the same time, a non-encounter: a failed meeting.

Derek Attridge argues that reading literature can be conceptualized as precisely this kind of encounter with strangeness, one which can elicit an opening up to alterity. In The Singularity of Literature, he writes that "it is the case, I believe, that some sense of strangeness, mystery or unfathomability is involved in every encounter with the literary" (Attridge 2004, 77). This strangeness results from an encounter with "otherness," or what Attridge defines as that which a particular culture at a particular moment must elide in order to maintain its

normative modes. Here, alterity is figured as that which is $[\ldots]$ outside the horizon provided by the culture for thinking, understanding, imagining, feeling, perceiving $[\ldots]$ produced in an active or event-like relation $[\ldots]$ that which the existing cultural order has to occlude in order to maintain its capacities and configurations, its value-systems and hierarchies of importance; that which it cannot afford to acknowledge if it is to continue without change. (Attridge 2004, 29, 30, 124)

While Attridge might certainly be correct in suggesting that particular works will be experienced as more or less strange given how hospitably they are received within a given socio-cultural context, it might very well also be the case that the ekphrastic impulse embedded within the process of literary production itself means that some literary works always, to some degree, remain epistemologically alien and are never fully culturally assimilated. My sense is that lists such as those we find in "Howl" encourage this process of estrangement and render the texts in which they are found more likely to be culturally received with this attunement to alterity. Certainly, while "Howl" is by this point firmly canonical and very often anthologized, it is also its queer content and explicit language that results in its marginalization both within and outside of the English literary studies classroom-as well as the larger cultural imaginary.

This is a poem that is not easily domesticated, a fact that is intimately bound up with the aesthetic form of the list itself. The list is what allows 
Ginsberg to poetically instantiate something as strange as "the game of the actual pingpong of the abyss" (Ginsberg 2008b, 114). We meet overly enumerative texts like Ginsberg's with a certain amount of trepidation; they are not easily absorbed, and they prove difficult for the task of the interpreter. These texts are restless and fidgety-somehow on edge. In the end, it is the list's ability to strangely point far beyond itself, to mark a kind of endlessness to the complexity of the representational gesture, that is perhaps most theoretically significant. These catalogues and enumerations, this paratactic and excessive prose, are ultimately able to open us to otherness: something strange-something else. The space of the list can thus become a space in which an egalitarian ethics might reside: a space where Ginsberg's "when you are not safe, I am not safe" becomes not just a utopian dream, but an ontological possibility.

\section{Notes}

1. "Listicle," Wikipedia. https://en.wikipedia.org/wiki/Listicle. Accessed 15 May 2016.

2. I am indebted to the Art Gallery of Ontario's 2015 Jean-Michel Basquiat exhibit "Now's the Time" for this rhetorical connection between King and Parker.

3. "Catatonia." Oxford English Dictionary, 2. https://www-oed-com.uwinnipeg.idm.oclc.org/view/Entry/28804? redirectedFrom=catatonia\#eid. Accessed 20 July 2015.

4. Ginsberg, "Wichita Vortex Sutra" in Collected Poems: 1947-1997 (2007), 92, 93, 96, 98 .

\section{REFERENCES}

Agamben, Giorgio. 2003. The Coming Community. Trans. Michael Hardt. Minneapolis: The University of Minnesota Press.

Attridge, Derek. 2004. The Singularity of Literature. London: Routledge.

"Catatonia." Oxford English Dictionary 2. https://www.oed.com.uwinnipeg.idm. oclc.org/view/Entry/28804? redirectedFrom=catatonia\#eid. Accessed 15 Jan 2020.

De Goede, Marieke, Anne Leander, and Gavin Sullivan. 2016. Introduction: The Politics of the List. Society and Space 34 (1): 3-13.

Eco, Umberto. 2009. The Infinity of Lists: An Illustrated Essay. New York: Rizzoli. 
Eliot, T.S. 2008. Burnt Norton. In The Norton Anthology of American Literature Volume 2: 1865-Present, shorter 7th ed., ed. Nina Baym, 885-889. New York: W. W. Norton \& Company.

Géfin, Laszlo. 2002. Ellipsis: The Ideograms of Ginsberg. In On the Poetry of Allen Ginsberg, ed. Lewis Hyde, 272-287. Ann Arbor: The University of Michigan Press.

Ginsberg, Allen. 2008a. Footnote to Howl. In The Norton Anthology of American Literature Volume 2: 1865-Present, shorter 7th ed., ed. Nina Baym, 1424. New York: W. W. Norton \& Company.

- 2008b. Howl. In The Norton Anthology of American Literature Volume 2: 1865-Present, shorter 7th ed., ed. Nina Baym, 1416-1424. New York: W. W. Norton \& Company.

—. 2007. Wichita Vortex Sutra. In Collected Poems: 1947-1997, 402-419. New York: Harper Collins.

Hunsberger, Bruce. 2002. Kit Smart's Howl. In On the Poetry of Allen Ginsberg, ed. Lewis Hyde, 158-170. Ann Arbor: The University of Michigan Press.

Joyce, James. 2003. A Portrait of the Artist as a Young Man. New York: Penguin Books.

Krieger, Murray. 2019. Ekphrasis and the Still Movement of Poetry; or Laokoon Revisited. In Ekphrasis: The Illusion of the Natural Sign, 263-288. Baltimore: The Johns Hopkins University Press.

"Listicle." Wikipedia. https://en.wikipedia.org/wiki/listicle. Accessed 15 May 2016.

Morton, Timothy. 2012. An Object-Oriented Defense of Poetry. New Literary History 43 (2): 205-224.

Spitzer, Leo. 1962. The Ode on a Grecian Urn, or Content vs Metagrammar. In Essays on English and American Literature, 67-97. Princeton: Princeton University Press. 
Open Access This chapter is licensed under the terms of the Creative Commons Attribution 4.0 International License (http://creativecommons.org/licenses/ by $/ 4.0 /$ ), which permits use, sharing, adaptation, distribution and reproduction in any medium or format, as long as you give appropriate credit to the original author(s) and the source, provide a link to the Creative Commons licence and indicate if changes were made.

The images or other third party material in this chapter are included in the chapter's Creative Commons licence, unless indicated otherwise in a credit line to the material. If material is not included in the chapter's Creative Commons licence and your intended use is not permitted by statutory regulation or exceeds the permitted use, you will need to obtain permission directly from the copyright holder. 